2016

\title{
Evidence for anti-intellectualism about know-how from a sentence recognition task
}

Ian Harmon

West Virginia University, ian.harmon@mail.wvu.edu

Zachary Horne

Arizona State University

Follow this and additional works at: https://researchrepository.wvu.edu/faculty_publications

Part of the Epistemology Commons, and the Philosophy of Mind Commons

\section{Digital Commons Citation}

Harmon, Ian and Horne, Zachary, "Evidence for anti-intellectualism about know-how from a sentence recognition task" (2016).

Faculty Scholarship. 920.

https://researchrepository.wvu.edu/faculty_publications/920

This Article is brought to you for free and open access by The Research Repository @ WVU. It has been accepted for inclusion in Faculty Scholarship by an authorized administrator of The Research Repository @ WVU. For more information, please contact ian.harmon@mail.wvu.edu. 


\title{
Evidence for anti-intellectualism about know-how from a sentence recognition task
}

\section{Ian Harmon and Zachary Horne}

\begin{abstract}
An emerging trend in cognitive science is to explore central epistemological questions using psychological methods. Early work in this growing area of research has revealed that epistemologists' theories of knowledge diverge in various ways from the ways in which ordinary people think of knowledge. Reflecting the practices of epistemology as a whole, the vast majority of these studies have focused on the concept of propositional knowledge, or knowledge-that. Many philosophers, however, have argued that knowing how to do something is importantly different from knowing that something is the case. Hence, in this paper we turn our attention to people's concept of knowledge-how. We present data from two experiments that employed a sentence recognition task as an implicit measure of conceptual activation. The data from this implicit measure suggest that, contrary to prominent intellectualist theories of know-how, according to which know-how is a species of propositional knowledge, people's concept of know-how more closely aligns with anti-intellectualism, the view that knowing how to perform some task consists in having the appropriate skills or abilities.
\end{abstract}

\section{Introduction}

One of the central aims of epistemology has been to analyze the concept of knowledge. Several types data have been brought to bear on this project, including analyses of epistemic language (e.g., Stanley \& Williamson, 2001), philosophers' intuitive responses to thought experiments, and more recently, the use of psychological methods to investigate how non-philosophers' conceive of knowledge (e.g., Buckwalter, 2012). This latter methodology is often employed with an eye towards determining if, and to what extent, philosophers' theories of knowledge map on to ordinary conceptions of knowledge.

However, like the bulk of mainstream epistemology, those using psychological methods have focused primarily on the parameters that affect people's concept of propositional knowledge, or knowledge-that (see Buckwalter, 2012). In contrast, people's concept of knowledge-how has received comparatively little attention (Bengson, Moffett, 
\& Wright, 2009).

There are two main camps in the debate about the constituent concepts of knowledge-how. One camp, intellectualism, argues that knowledge-how involves propositional knowledge (e.g. Bengson \& Moffett, 2007; Bengson, Moffett, \& Wright, 2009; Stanley, 2011; Stanley \& Williamson, 2001), whereas the competing camp argues that knowledge-how does not involve propositional knowledge - a view called antiintellectualism. According to anti-intellectualists, whereas propositional knowledge is a certain type of belief, knowledge-how consists in abilities, skills, or dispositions (Noë, 2005).

In recent years philosophers have defended intellectualism on both linguistic and empirical grounds. Stanley \& Williamson (2001) and Stanley (2011), for instance, draw on Karttunen's (1977) linguistic analysis of embedded questions to argue that sentences containing know-how ascriptions should be analyzed as ascriptions of propositional knowledge. For instance, on this view sentences of the form:

(1) Hannah knows how to ride a bicycle.

should be analyzed as:

(2) Hannah knows that some way, $w$, is a way for her to ride a bicycle.

Since (2) is a propositional knowledge ascription, and is allegedly the appropriate analysis of (1), Stanley and Williamson conclude that knowing-how requires propositional knowledge. ${ }^{1}$

\footnotetext{
${ }^{1}$ This, of course, is not a complete account of Stanley and Williamson's position. They believe there to be cases in which (2) is true, but in which Hannah does not know how to ride a bicycle. In addition to (2) being true, in order for Hannah to know how to ride a bicycle, she must entertain the proposition in (2) under a practical mode of presentation. Nevertheless, we hope this brief summary makes it clear how Stanley and Williamson argue for the claim that propositional knowledge is necessary for knowing how.
} 
Stanley and Williamson's account of knowledge-how has proved quite influential in the last decade, but some philosophers have worried that their linguistic analysis does not accurately reflect people's concepts. Alva Noë offers a succinct expression of this sort of criticism (2005). In response to Stanley and Williamson's claim that a ski instructor may know how to perform ski stunts despite lacking the corresponding ability, Noë writes, “Is it Stanley and Williamson's view that, if polled, most English speakers would share the intuition that the instructor is unable to do the jumps even though she knows how to do the jumps? I would predict that this is not true," (Noë, 2005, 283).

Recently, Bengson, Moffett, and Wright (2009) sought to test Noë's prediction by examining people's intuitions about what constitutes knowledge-how. Bengson and colleagues presented participants with a short story about a ski instructor who lacked the ability to perform the ski stunts he successfully taught to others. After reading the story, participants were asked whether the instructor knew how to perform ski stunts and whether they lacked the ability to perform them. Contrary to Noë's prediction, Bengson and colleagues found that the majority of participants judged both that the ski instructor knows how to perform the stunts and that he does not have the ability to perform them himself. This result was quite surprising as traditionally many psychological theories had posited a distinction between knowledge-that and knowledge-how (Cohen \& Squire, 1980).

Although Bengson and colleagues' empirical survey provides some support for intellectualism, the study is subject to two potential concerns and that call for further empirical research. First, it does not appear that measures were taken to conceal the aim of the study from participants. When a study's aim can be guessed by its participants, the 
results may owe to demand characteristics, which are artifacts of the study design that lead participants to perform the study in a manner that is consistent with the experimental hypothesis (Firestone \& Scholl, 2013; Orne, 1962; Powell et al., 2015). When demand characteristics cannot be ruled out, it is difficult to determine whether participants' judgments provide evidence for the hypothesis in question or whether participants have merely guessed the aim of the study and behaved in a way consistent with their guess. Consequently, it is unclear whether Bengson and colleagues' study provides evidence for an intellectualist concept of knowledge-how, or whether participants guessed the aim of the experiment and made judgments consistent with the experimenters' hypotheses. ${ }^{2}$ This is not just a theoretical worry: Even in studies in which the manipulation in question is subtle - especially compared to the manipulations typically employed in experimental philosophy - participants can guess the aim of an experiment and answer in a fashion that is consistent with the researchers' hypotheses (e.g., Firestone \& Scholl, 2013).

Second, as is the case in much of experimental philosophy, Bengson and colleagues' study attempts to reveal people's intuitions about knowledge-how by asking participants to make judgments about thought experiments. However, because people's judgments are downstream from their concepts, data gathered in this manner may reflect unthoughtful reactions to difficult philosophical issues rather than their intuitions or concepts (see Cullen, 2010; Kauppinen, 2007; Powell, Horne, \& Pinillos, 2014; Powell, Horne, Pinillos, \& Holyoak, 2015; Sosa, 2007 for similar criticisms).

In sum, these two issues signal the need for further empirical research on people's

\footnotetext{
${ }^{2}$ While we think it is quite plausible that demand characteristics can explain Bengson and colleagues' observed effects, we are not arguing that experimental demands do in fact explain their effect. Further empirical research is needed to assess this alternative hypothesis.
} 
concept of knowledge-how. In the remainder of the paper, we discuss two experiments aimed at addressing this need.

\section{The Present Study}

Our aim is to reexamine how people think about knowledge-how by using a measure that avoids demand characteristics and more directly reflects people's concepts. ${ }^{3}$ Rather than using a standard survey measure, we employed an implicit measure of conceptual activation called semantic integration (Gentner, 1981; Powell et al., 2013; Powell et al., 2014; Waskan et al., 2014). Semantic integration is the cognitive process by which units of semantic information are combined to form more complex structured representations. Prior psychological research has shown that when people read sentences within a larger context (i.e., a passage), individual sentences are not encoded in isolation, but instead their meanings are concatenated to form a coherent semantic whole (e.g., Bransford \& Franks, 1974; Gentner, 1981). Other related studies have shown that people's memory for semantic content tends to be more robust than their memory for the syntactic structure of individual sentences (e.g., Sachs, 1967). Thus, when participants are asked to remember a passage of text after a delay, what they remember reflects their semantic interpretations of the passage they read rather than the actual sentences they read. For example, Bransford and Franks (1971) found that reading several interrelated sentences (e.g., "The frog was on the log" and "The fish swam under the log") caused participants to falsely recognize sentences that could be inferred from a combination of

\footnotetext{
${ }^{3}$ We note that while our interest in this paper is primarily psychological, we assume there is an important connection between the psychological and the linguistic support for intellectualist theories of knowledgehow. This connection is illustrated by the fact that there is a clear sense in which Bengson et al.'s study was designed to test the descriptive accuracy of Stanley and Williamson's linguistic analysis.
} 
those two sentences (e.g., "The fish swam under the frog"). In a task that was analogous to the one employed by Bransford and Franks, we investigated people's concept of knowledge-how by using a sentence recognition task as a measure of semantic integration.

Semantic integration imposes fewer demand characteristics on participants than traditional survey methods because participants are led to believe they are completing a reading comprehension or memory task. Moreover, semantic integration tasks do not raise any concerns that participants' responses are the product of unthoughtful reactions to philosophical thought experiments; instead the data from integration tasks reflect the concepts activated when participants passively encode the story they are asked to read. In short, unlike traditional survey measures, data from semantic integration tasks is not subject to the worry that it is the product of responses that are not reflective of participants' concepts.

In the present studies, we used a sentence recognition task as an implicit measure of semantic integration. In a $2 \times 2$ between-subjects design, participants were asked to read a story about a ski instructor (Experiment 1) or a chess instructor (Experiment 2). ${ }^{4}$ Depending on the condition participants were assigned to, they would read a story in which the instructor has both propositional knowledge about and an ability to perform the task in question (KNOW-HOW), only propositional knowledge (INT) but no ability, only the ability (ANTI) but false beliefs about how one performs the stunts, or no ability and

\footnotetext{
${ }^{4}$ Ideally, we would have been able to use the same materials as Bengson et al. to test our hypotheses. However, semantic integration tasks preclude this possibility. If a vignette is particularly short, as Bengson and colleagues' are, then it is unlikely participants will falsely remember any sentence as appearing in the story that did not in fact appear. This would likely lead to floor effects that would make it difficult to discern any condition-level differences. In light of this issue, we attempted to strike a balance between developing a vignette that was appropriate for a semantic integration paradigm and that included elements similar to those in Bengson et al.'s vignettes.
} 
false beliefs about how one performs the stunts (NO KNOW-HOW). After reading a distractor story and answering comprehension questions about it, participants were asked to indicate whether a series of sentences had appeared in the story about the instructor. Following prior semantic integration designs (e.g., Powell et al., 2014; Powell et al., 2015; Waskan et al., 2014), our hypothesis was that the version of the story people read (i.e. the condition they were assigned to) would influence what they encoded about the instructor.

\section{Predictions}

We predicted that participants would incorrectly think that a sentence had appeared in the story (false alarm) when the sentence fit with what they semantically encoded about the story. Specifically, we hypothesized that participants would incorrectly think that a sentence saying that an instructor knew how to perform a task (the critical sentence) was present in the story they read when the sentence fit with what they semantically encoded about the story (Bransford \& Franks, 1974; Powell et al., 2014; Powell et al., 2015; Waskan et al., 2014). By comparing participants' false alarm rates on the critical sentence across conditions, as well as their overall false alarms on other control sentences, we were able to measure the degree to which these stories differentially led participants to encode that the instructor knows how. Thus, using this method we are able to determine what factors - ability or propositional knowledge - lead participants to more frequently encode that an instructor knows-how.

We predicted that ability, rather than propositional knowledge, would lead participants to encode that an instructor knew-how. In other words, we predicted a main effect of ability on the proportion of false alarms to the critical sentence, and no effect of 
propositional knowledge. In addition, we predicted that there would be a greater proportion of false alarms on the critical sentence for the ANTI condition than for the INT condition.

\section{Experiment 1}

Participants

Participants were 208 workers recruited on Amazon Mechanical Turk. Fifty percent of participants were female. The mean age of participants was 35.6 years old. Procedure and Materials

Participants read one of four versions of a story about a ski instructor, Patrick, teaching a student how to perform ski stunts. Participants' task was to read this story and remember it to the best of their ability. After reading a distractor story (a popular science article on gamma ray bursts) and answering comprehension questions about it, they were asked to judge whether a series of sentences (randomly ordered) appeared in the story about the ski instructor. During this sentence recognition phase, sentences were presented to participants in bold and they were forced to choose either, "Yes, this sentence appeared in the story," or, "No, this sentence did not appear in the story."

In addition to presenting the critical sentence to participants, we also included several control sentences. One of these sentences (the teacher sentence) read, "Patrick was definitely a great teacher." This was included to ensure that participants did not assume the ski instructor was a better teacher in virtue of having the ability to perform the stunts in conditions where he did indeed have this ability. It was important to include this sentence because a difference in how participants perceived the quality of Patrick as a teacher could spuriously drive a difference in false alarm rates to the critical sentence. 
The other control sentences were included to rule out the possibility that some versions of the story were more difficult to remember than others.

Results

Of the original 208 participants, two participants' control sentence recognition scores were more than three standard deviations from the mean control sentence score. These participants were removed before performing subsequent analyses. However, all of our effects remain significant even if these participants are included in the analyses.

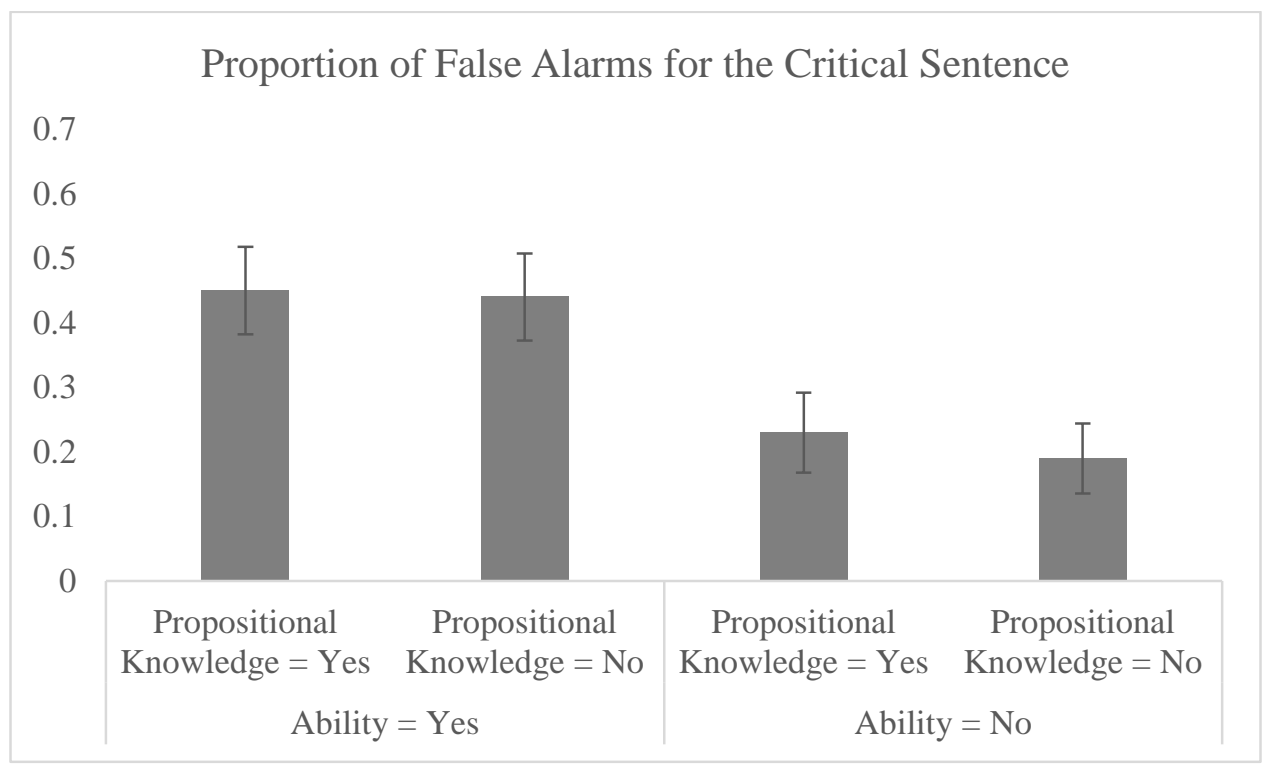

Figure 1. The proportion of false alarm rates for the critical sentence "It was clear that Patrick knew how to perform ski stunts".

We predicted that we would observe a main effect of ability on false alarms for the critical sentence, but no effect of propositional knowledge and no interaction between these factors. Because our main dependent variable was dichotomous - whether you false alarmed to the critical sentence - we used logistic regression to examine the effect of ability and propositional knowledge on false alarms to the critical sentence. Consistent with our predictions, this analysis revealed a main effect of ability on false alarms to the 
critical sentence (Wald $\left.\chi^{2}(1)=13.705, p<.001\right)$. Contrary to the intellectualist account of know-how, we observed no main effect of propositional knowledge on false alarms for the critical sentence (Wald $\chi^{2}(1)=.131, p=.718$ ), nor did we observe a significant interaction between these factors (Wald $\left.\chi^{2}(1)=.016, p=.90\right)$.

Since it is possible this main effect could be driven by the KNOW-HOW condition, we wanted to confirm that the ANTI condition led to higher proportion of false alarms than the INT condition. A $\chi^{2}$ test revealed that the ANTI condition had significantly more false alarms to the critical sentence than the INT condition $\left(\chi^{2}(1, N=\right.$ 101) $=4.91, p=.026)$.

Table 1. The proportion of false alarms for the Teacher and the Control sentences.

\begin{tabular}{cccccc}
\hline & & \multicolumn{2}{c}{ Teacher Sentence } & \multicolumn{2}{c}{ Control Sentences } \\
\cline { 3 - 6 } Ability & $\begin{array}{l}\text { Propositional } \\
\text { Knowledge }\end{array}$ & False Alarms & SE & False Alarms & SE \\
\hline \multirow{2}{*}{ Yes } & Yes & .47 & .067 & .19 & .025 \\
& No & .48 & .067 & .12 & .018 \\
No & Yes & .62 & .071 & .14 & .022 \\
& No & .21 & .056 & .20 & .021 \\
\hline
\end{tabular}

As shown in Table 1, these effects cannot be attributed to an overall difference in recognition performance since we observed no main effect of condition on control sentence performance $(F(3,204)=2.49, p>.05)$, nor can it be attributed to any difference in participants attributing more skill to Patrick as a teacher since the ANTI 
condition did not differ from the INT condition on false alarms for the teacher sentence $\left(\chi^{2}(1, N=101)=2.39, p>.1\right) .^{5}$

Our results indicate that, contrary to what prior empirical research on people's concept of knowledge-how should lead us to expect (i.e., Bengson et al., 2009), people encoded that an instructor knew how when the instructor had the ability to perform the stunts, but false beliefs about how he performed them, compared to participants who read a story in which the instructor had the correct beliefs about how to perform the stunts but no ability to perform them.

\section{Experiment 2}

\section{Participants}

Participants were 213 workers recruited on Amazon Mechanical Turk. Fifty-One percent of participants were female. The mean age of participants was 33.3.

\section{Procedure and Materials}

Experiment 2 used the same methods and analyses as experiment 1. However, rather than using the ski instructor story we used a story about a chess instructor. Chess is, intuitively, a more intellectual activity than skiing, and we wanted to test the possibility that people's concept of know-how might be task-specific. In other words, one possibility is that people think that knowing how to do physical tasks, such as ski stunts, consists in having the appropriate ability, whereas they may think that knowing how to do more intellectual activities, such as playing chess, consists in knowing the right rules

\footnotetext{
${ }^{5}$ In fact, participants were more likely to encode that Patrick was a great teacher in the intellectualism condition than the anti-intellectualism condition, though this difference was not reliable. Moreover, participants' overall control sentence score was actually better (though non-significantly) in the ANTI condition than the INT condition, so it is not as if participants in the ANTI condition were simply worse at remembering what occurred in the story than in the INT condition.
} 
and strategies, that is, in having propositional knowledge. Nevertheless, if an antiintellectualist story still leads to a higher proportion of false alarms for the critical sentence in a paradigmatically intellectual activity, this would indicate that people still think knowledge-how is more tightly connected to having an ability than to having knowledge-that. Thus, in experiment 2, Patrick was a chess instructor who trained a student how to play chess. Everything else about the task was the same.

Results

Of the original 213 participants, two participants' control sentence recognition scores were more than three standard deviations from the mean score. These participants were removed before performing any analyses. However, all of our effects (and noneffects) remain unchanged even if we include these participants in our analyses.

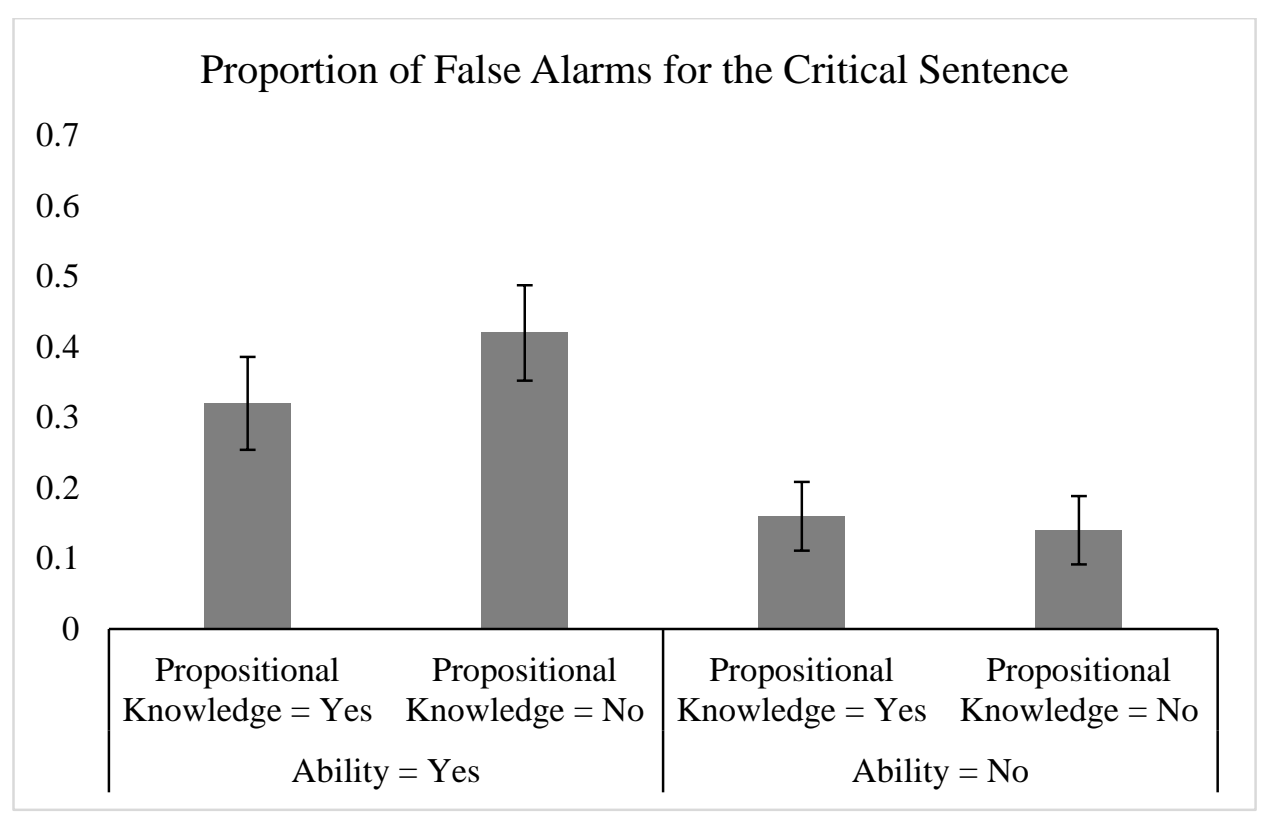

Figure 2: The proportion of false alarms for the critical sentence "It was clear that Patrick knew how to play chess".

As in experiment 1 , our dependent variable was dichotomous so we again used logistic regression to examine the effect of ability and propositional knowledge on false alarms to 
the critical sentence. Consistent with anti-intellectualism about know-how, this analysis revealed a main effect of ability on false alarms for the critical sentence (Wald $\chi^{2}(1)=$ 12.49, $p<.001)$. Against the intellectualist account of know-how, we observed no effect of having propositional knowledge about chess on false alarms for the critical sentence $\left(\right.$ Wald $\left.\chi^{2}(1)=.13, p=.718\right)$, nor any interaction between these factors (Wald $\chi^{2}(1)=$ $.708, p=.40)$.

Following up on this main effect, a $\chi^{2}$ test revealed that the ANTI condition again led to significantly more false alarms to the critical sentence than the INT condition $\left(\chi^{2}\right.$ $(1, N=110)=8.97, p=.002)$, suggesting that the main effect of ability was not solely driven by the KNOW HOW condition.

Table 2. The proportion of false alarms for the Teacher and Control sentences.

\begin{tabular}{cccccc}
\hline & & \multicolumn{2}{c}{ Teacher Sentence } & \multicolumn{2}{c}{ Control Sentences } \\
\cline { 3 - 5 } Ability & $\begin{array}{l}\text { Propositional } \\
\text { Knowledge }\end{array}$ & False Alarms & SE & $\begin{array}{c}\text { False } \\
\text { Alarms }\end{array}$ & SE \\
Yes & Yes & .56 & .071 & .20 & .023 \\
\cline { 3 - 5 } & No & .58 & .067 & .22 & .021 \\
No & Yes & .58 & .063 & .20 & .019 \\
& No & .14 & .048 & .22 & .025 \\
\hline
\end{tabular}

We also found that this effect cannot be attributed to an overall difference in the difficulty of remembering these stories since we observed no effect of condition on control sentences $(F(3,207)=.227, n s)$, nor can it be attributed in any difference in participants attributing more skill to Patrick as a teacher, since there was no significant difference in false alarm rates for the teacher sentence comparing the ANTI and INT 
conditions $\left(\chi^{2}(1, N=110)=.004, n s\right)$.

Contrary to the conjecture that people will have a more intellectualist conception of know-how in a paradigmatically intellectual domain, reading the ANTI story still led to more false alarms for the critical sentence than reading the INT story. Even in the case of chess, participants semantically encoded that the instructor knew how to play chess when he had the ability to play chess (and false beliefs about how he executed chess moves). In contrast, participants' false alarm rates in the INT condition were not significantly higher than they were in the NO KNOW-HOW condition, suggesting that having the correct beliefs about how to perform a task does not lead people to encode that one knows-how.

\section{Discussion}

In the last several years the question of what types of mental states are constitutive of knowledge-how has received a good deal of attention from epistemologists and philosophers of mind. Intellectualists have argued that knowing how to, for instance, ride a bicycle consists in having the right propositional knowledge about bicycle riding. Anti-intellectualists, on the other hand, have argued that knowing how to ride a bicycle consists in having the ability to ride a bicycle. Here, we have discussed two kinds of evidence for intellectualism - linguistic and psychological. The present empirical research, however, may call this evidence into question.

First, our results directly contradict those of Bengson et al. (2009). Whereas Bengson et al. (2009) found that the majority of their participants made judgments consistent with intellectualism, we found that people are far more likely to semantically encode that an instructor knows how in cases where they have the ability to do a task, 
despite having false beliefs about the task, than in cases where they have propositional knowledge about the task but lack the ability to perform it. This, in and of itself, indicates that there is at least equal psychological support for intellectualist and anti-intellectualist accounts of knowledge-how. However, our study has the additional virtue of ruling out alternative hypotheses and more directly reflecting participants' concepts. In other words, the very structure of our task yields results that more directly reflect people's concepts (e.g., Powell et al., 2014; Powell et al., 2015). In contrast, we suggest that Bengson and colleague's results can be explained by appealing to demand characteristics that were not ruled out by the design of their study. ${ }^{6}$

Second, our results raise questions about the descriptive accuracy of Stanley and Williamson's linguistic analysis. If their analysis were descriptively accurate, then participants should have had a higher proportion of false alarms to the critical sentence for stories in which a subject has propositional knowledge (but no ability) about a task than in cases where a subject has the ability (but lacks propositional knowledge) about a task. This, of course, is the opposite of what we found. Hence, our data puts pressure on the descriptive accuracy of their linguistic analysis.

\section{Directions for Future Research}

Above we suggested that the divergence between our results and those of Bengson and colleagues can be explained by the fact that their study fails to rule out the influence of demand characteristics, whereas ours does not. This, of course, is not the

\footnotetext{
${ }^{6}$ Our study also avoids the concern that participants are making judgments that reflect pragmatic factors downstream from their concepts (a concern Bengson himself has raised about experimental philosophy, Bengson, 2013).
} 
only plausible explanation for this divergence. In this section, we discuss an alternative explanation, as well as other concerns about our results, and suggest some directions for future research.

An alternative explanation of the divergence between our results and those of Bengson and colleagues is to appeal to the differences in the stimuli used in the studies. In their stimuli, Bengson and colleagues describe their protagonist as having highly developed and closely related abilities. For instance, in their ski instructor case, the instructor is described as being an accomplished skier. Our stimuli do not include information regarding highly developed and closely related abilities. It's possible that in cases where ability is absent, the likelihood of attributing knowledge-how will vary with the distance between the actual case and the counterfactual case in which the subject has the ability (e.g., Wallis, 2008; Williams, 2007). Future research should investigate how these counterfactual differences affect people's attributions of knowledge-how to a subject.

Another potential worry about the interpretation of our results stems from the fact that in our ANTI and NO KNOW-HOW vignettes the instructor is described as having false beliefs about the task in question, which is compatible with his also possessing propositional knowledge about the task. Because of this, it is possible that our participants believe that the instructor still possesses propositional knowledge about the task in question and that this belief influences their false alarm rates on the critical sentence.

While the vignettes are compatible with this possibility, they do not weaken the importance of our results. If participants believed that the instructor possesses 
propositional knowledge even when he has false beliefs about the task - and importantly, this influenced their false recognition rates - then there should have been some effect of propositional knowledge on false alarm rates for the critical sentence. However, we observed no trace of such an effect. Instead, it appears that whether the instructor has propositional knowledge or not has little effect on whether participants attributed knowhow to him. Still, further research is necessary to determine the ways in which the propositional knowledge a subject has can influence know-how attributions.

\section{Conclusion}

In recent years philosophers have turned to the methods of empirical psychology to investigate how people think about knowledge. However, only one study, that of Bengson and colleagues', has examined how non-philosophers think about knowledgehow. This study suggests that people tend to think of know-how in an intellectualist manner, that is, they tend to think knowing-how involves propositional knowledge.

In this paper we have provided evidence for anti-intellectualism using a novel experimental method that avoids two concerns to which Bengson and colleagues' study is subject. While our results certainly do not offer the final word on the issue, we hope to have advanced the empirical study of know-how and to have provided guidance for further research. 


\section{References}

Bengson, J. (2013). Experimental attacks on intuitions and answers. Philosophy and Phenomenological Research, 86(3), 495-532.

Bengson, J., \& Moffett, M. A. (2007). Know-how and concept possession. Philosophical Studies, 136 (1), 31-57.

Bengson, J., Moffett, M. A., \& Wright, J. C. (2009). The folk on knowing how. Philosophical Studies, 142(3), 387-401.

Buckwalter, W. (2012). Non-Traditional Factors in Judgments about Knowledge. Philosophy compass, 7(4), 278-289.

Bransford, J. D., Barclay, J. R., \& Franks, J. J. (1972). Sentence memory: A constructive versus interpretive approach. Cognitive psychology, 3(2), 193-209.

Firestone, C., \& Scholl, B. J. (2014). “Top-Down” Effects Where None Should Be Found The El Greco Fallacy in Perception Research. Psychological science, 25(1), 3846.

Gentner, D. (1981). Integrating verb meanings into context. Discourse processes, 4(4), 349-375.

Karttunen, L. (1977). Syntax and semantics of questions. Linguistics and philosophy, 1(1), 3-44.

Kauppinen, A. (2007). The rise and fall of experimental philosophy. Philosophical explorations, 10(2), 95-118.

Orne, M. T. (1962). On the social psychology of the psychological experiment: With particular reference to demand characteristics and their implications. American psychologist, 17(11), 776.

Powell, D., Horne, Z., \& Pinillos, N. A. (2014). Semantic integration as a method for investigating concepts. In Beebe (Ed.) Advances in Experimental Epistemology, New York: Continuum Press.

Powell, D., Horne, Z., Pinillos, N. Á., \& Holyoak, K. J. (2015). A Bayesian framework for knowledge attribution: Evidence from semantic integration. Cognition, 139, 92-104.

Ryle, G. (1945). Knowing how and knowing that: The presidential address. In Proceedings of the Aristotelian Society (pp. 1-16). Harrison \& Sons, Ltd.

Ryle, G. (1949). The concept of mind. New York: Barnes \& Noble. 
Sachs, J. S. (1967). Recopition memory for syntactic and semantic aspects of connected discourse. Perception \& Psychophysics, 2(9), 437-442.

Stanley, J. (2011). Know how. New York: Oxford University Press.

Stanley, J., \& Williamson, T. (2001). Knowing how. The Journal of Philosophy, 411444.

Waskan, J., Harmon, I., Horne, Z., Spino, J., \& Clevenger, J. (2014). Explanatory antipsychologism overturned by lay and scientific case classifications. Synthese, 191(5), 1013-1035.

Wallis, C. (2008). Consciousness, context, and know-how. Synthese, 160(1), 123-153.

Weber, S. J., \& Cook, T. D. (1972). Subject effects in laboratory research: An examination of subject roles, demand characteristics, and valid inference. Psychological Bulletin, 77(4), 273.

Williams, J. N. (2008). Propositional knowledge and know-how. Synthese, 165(1), 107125.

\section{Appendix A}

\section{Experiment 1 KNOW-HOW CONDITION (Ability-Yes, Beliefs-True)}

Bill arrived at the Falcon's Nest Ski Lodge after a long, dreary day of travel. Bill had always been an irritable traveler, and sitting through a six-hour delay at Chicago's 
O'Hare airport only reinforced his foul mood. However, Bill was ready to put the stresses of travel behind him and settle in for the night in his suite at the lodge.

When he entered his room, number 407, he was pleasantly surprised to find a welcome basket sitting on the counter in the kitchenette. Next to the basket was a state of the art hot chocolate maker. Although Bill was exhausted, and had a long day planned on the slopes beginning early the next morning, he couldn't help but indulge in the room's amenities before hitting the sack. Unfortunately, despite the impressive appearance of the hot chocolate machine, the quality of the beverage produced was disappointing. "Oh well," Bill thought, "I didn't come here to drink hot chocolate anyway." He then went to bed, ready to begin his ski lesson the next morning.

Bill arrived at the slopes at 8 AM the following day to meet his ski instructor, Patrick. Bill still couldn't believe his luck at finding an opening in Patrick's schedule. Patrick had been a ski instructor for 20 years, specializing in teaching people how to perform complex ski stunts. Patrick was always in high demand as an instructor, having a reputation of being the best in the business.

While Bill had long been aware of Patrick's teaching credentials, he learned that Patrick was capable of performing ski stunts himself. In fact, Patrick had competed in several international competitions, including the Olympics on multiple occasions. And several of Patrick's former students had gone on to compete successfully in many world-class competitions.

Patrick had developed an interest in skiing at a very early age after his family went on vacation to Breckenridge, Colorado. Ever since then, he spent nearly all of his free time both practicing ski stunts and studying the theory and technique, including some basic physics, of skiing. For instance, he correctly thought that the way he performs ski jumps was by bending his knees at the end of the ramp. After years of both study and practice, Patrick developed an international reputation for being among the best ski stunt instructors in the world.

After a week of training under Patrick, Bill was amazed at how much he had learned and how reliable he had become at executing some of the most complex of ski stunts. Three weeks later, he put his new skills to the test, placing first in the Greater Mountain West Invitational held near Salt Lake City, Utah. "I couldn't have done it without Patrick," thought Bill. "I'll have to send him a thank you card."

\section{Experiment 1 ANTI Condition (Ability-Yes, Beliefs-False)}

Bill arrived at the Falcon's Nest Ski Lodge after a long, dreary day of travel. Bill had always been an irritable traveler, and sitting through a six-hour delay at Chicago's O'Hare airport only reinforced his foul mood. However, Bill was ready to put the stresses of travel behind him and settle in for the night in his suite at the lodge. 
When he entered his room, number 407, he was pleasantly surprised to find a welcome basket sitting on the counter in the kitchenette. Next to the basket was a state of the art hot chocolate maker. Although Bill was exhausted, and had a long day planned on the slopes beginning early the next morning, he couldn't help but indulge in the room's amenities before hitting the sack. Unfortunately, despite the impressive appearance of the hot chocolate machine, the quality of the beverage produced was disappointing. "Oh well," Bill thought, "I didn't come here to drink hot chocolate anyway." He then went to bed, ready to begin his ski lesson the next morning.

Bill arrived at the slopes at 8 AM the following day to meet his ski instructor, Patrick. Bill still couldn't believe his luck at finding an opening in Patrick's schedule. Patrick had been a ski instructor for 20 years, specializing in teaching people how to perform complex ski stunts. Patrick was always in high demand as an instructor, having a reputation of being the best in the business.

While Bill had long been aware of Patrick's teaching credentials, he learned that Patrick was capable of performing ski stunts himself. In fact, Patrick had competed in several international competitions, including the Olympics on multiple occasions. However, Patrick spent nearly all of his free time practicing skiing, and no time studying the science and technique behind the sport. Nevertheless, several of Patrick's former students had gone on to compete successfully in various world-class competitions.

Patrick had developed an interest in skiing at a very early age after his family went on vacation to Breckenridge, Colorado. Ever since then, he spent nearly all of his free time practicing ski stunts but not studying the theory and technique of skiing. For instance, he incorrectly thought that the way he performed ski jumps was by bending his knees at the end of the ramp. After years of both training and practice, Patrick developed an international reputation for being among the best ski stunt instructors in the world.

After a week of training under Patrick, Bill was amazed at how much he had learned and how reliable he had become at executing some of the most complex of ski stunts. Three weeks later, he put his new skills to the test, placing first in the Greater Mountain West Invitational held near Salt Lake City, Utah. "I couldn't have done it without Patrick," thought Bill. "I'll have to send him a thank you card."

\section{Experiment 1 NO KNOW-HOW Condition (Ability-No, Beliefs-False)}

Bill arrived at the Falcon's Nest Ski Lodge after a long dreary day of travel. Bill had always been an irritable traveler, and sitting through a six hour delay at Chicago's O'Hare airport only reinforced his mood. However, Bill was ready to put the stresses of travel behind him, and settle in for the night in his suite at the lodge.

Although Bill was exhausted, and had a long day planned on the slopes beginning early the next morning, he couldn't help but indulge in the lodge's amenities before hitting the sack. When he entered his room, number 407 , he was pleasantly surprised to find a welcome basket sitting on the counter in the kitchenette. Next to the basket was a state of the art hot chocolate maker. Unfortunately, despite the impressive appearance of the hot 
chocolate machine, the quality of the beverage produced was disappointing. "Oh well," he thought, "I didn't come here to drink hot chocolate anyway." He then went to bed, ready to begin his skiing the next morning.

Bill arrived at the slopes at 8 AM the following day to meet his ski instructor, Patrick. Bill still couldn't believe his luck at finding an opening in Patrick's schedule. Bill had heard that Patrick had been a ski instructor for 20 years, specializing in teaching people how to perform complex ski stunts. Supposedly, Patrick was always in high demand as an instructor, having a reputation of being the best in the business.

While Bill had heard lots of hype about Patrick's teaching credentials, he learned that Patrick was incapable of performing ski stunts himself. In fact, Patrick hadn't even coached in any international competitions, and certainly not the Olympics on any occasion. And none of Patrick's former students had gone on to compete successfully in any world-class competitions.

Patrick had developed an interest in skiing at a very early age after his family went on vacation to Breckenridge, Colorado. Ever since then, however, he spent no time practicing ski stunts or studying the theory and technique of skiing. For instance, he incorrectly thought that the way one performs ski jumps was by bending one's knees at the end of the ramp. But after years of both hype and self promotion, Patrick developed an international reputation for being among the best ski stunt instructors in the world. In reality, Patrick spent most of his time hanging out in the ski lodge flirting with women.

After a week of "training" under Patrick, Bill was amazed at how little he had learned and how unreliable he had become at executing some of the most simple of ski stunts. Three weeks later, he put his new "skills" to the test, placing last in the Greater Mountain West Invitational held near Salt Lake City, Utah. "I couldn't have done it without Patrick," Bill bitterly thought. "I'll have to send him a thank you card."

\section{Experiment 1 INT Condition (Ability-No, Beliefs-True)}

Bill arrived at the Falcon's Nest Ski Lodge after a long, dreary day of travel. Bill had always been an irritable traveler, and sitting through a six-hour delay at Chicago's O'Hare airport only reinforced his foul mood. However, Bill was ready to put the stresses of travel behind him and settle in for the night in his suite at the lodge.

When he entered his room, number 407 , he was pleasantly surprised to find a welcome basket sitting on the counter in the kitchenette. Next to the basket was a state of the art hot chocolate maker. Although Bill was exhausted, and had a long day planned on the slopes beginning early the next morning, he couldn't help but indulge in the room's amenities before hitting the sack. Unfortunately, despite the impressive appearance of the hot chocolate machine, the quality of the beverage produced was disappointing. "Oh well," Bill thought, "I didn't come here to drink hot chocolate anyway." He then went to bed, ready to begin his ski lesson the next morning. 
Bill arrived at the slopes at 8 AM the following day to meet his ski instructor, Patrick. Bill still couldn't believe his luck at finding an opening in Patrick's schedule. Patrick had been a ski instructor for 20 years, specializing in teaching people how to perform complex ski stunts. Patrick was always in high demand as an instructor, having a reputation of being the best in the business.

While Bill had long been aware of Patrick's teaching credentials, he learned that Patrick was incapable of performing ski stunts himself. Patrick had coached in several international competitions, including the Olympics on multiple occasions. However, Patrick had never had the ability to perform ski stunts himself, despite his extensive expertise and success at teaching others to do so. Nevertheless, several of Patrick's former students had gone on to compete successfully in many world-class competitions.

Patrick had developed an interest in skiing at a very early age after his family went on vacation to Breckenridge, Colorado. Ever since then, he spent nearly all of his free time both reading about ski stunts, and studying the theory and technique, including some basic physics, of skiing. For instance, he correctly thought that the way one performs ski jumps is by bending one's knees at the end of the ramp. After years of both study and research, Patrick developed an international reputation for being among the best ski stunt instructors in the world.

After a week of training under Patrick, Bill was amazed at how much he had learned and how reliable he had become at executing some of the most complex of ski stunts. Three weeks later, he put his new skills to the test, placing first in the Greater Mountain West Invitational held near Salt Lake City, Utah. "I couldn't have done it without Patrick," thought Bill. "I'll have to send him a thank you card."

\section{Experiment 2 KNOW-HOW Condition (Ability-Yes, Beliefs-True)}

Bill arrived at the Midwestern Chess Academy after a long, dreary day of travel. Bill had always been an irritable traveler, and sitting through a six-hour delay at Chicago's O'Hare airport only reinforced his foul mood. However, Bill was ready to put the stresses of travel behind him and settle in for the night in his hotel room.

When he entered his room, number 407, he was pleasantly surprised to find a welcome basket sitting on the counter in the kitchenette. Next to the basket was a state of the art hot chocolate maker. Although Bill was exhausted, and had a long day of chess beginning early the next morning, he couldn't help but indulge in the room's amenities before hitting the sack. Unfortunately, despite the impressive appearance of the hot chocolate machine, the quality of the beverage produced was disappointing. "Oh well," Bill thought, "I didn't come here to drink hot chocolate anyway." He then went to bed, ready to begin his chess lesson the next morning.

Bill arrived at the lesson at $8 \mathrm{AM}$ the following day to meet his chess instructor, Patrick. Bill still couldn't believe his luck at finding an opening in Patrick's schedule. Patrick had been a chess instructor for 20 years, specializing in teaching people opening 
strategies. Patrick was always in high demand as an instructor, having a reputation for being the best in the business.

While Bill had long been aware of Patrick's teaching credentials, he learned that Patrick excelled at playing chess as well. In fact, Patrick had competed in several international competitions, including the World Championship on multiple occasions. And several of Patrick's former students had gone on to compete successfully in many world-class competitions.

Patrick had developed an interest in chess at a very early age after his family took a trip to the National Chess Hall of Fame. Ever since then, he spent nearly all of his free time both practicing chess and studying the theory and technique, including some basic game theory, of chess. For instance, he correctly thought he won matches by controlling the center of the board. After years of both study and practice, Patrick developed an international reputation for being among the best chess instructors in the world.

After a week of training under Patrick, Bill was amazed at how much he had learned and how intuitive executing the most complex of chess openings became. Three weeks later, he put his new skills to the test, placing first in the Greater Midwest Chess Tournament held near Milwaukee, Wisconsin. "I couldn't have done it without Patrick," thought Bill. "I'll have to send him a thank you card.

\section{Experiment 2 ANTI Condition (Ability-Yes, Beliefs-False)}

Bill arrived at the Midwestern Chess Academy after a long, dreary day of travel. Bill had always been an irritable traveler, and sitting through a six-hour delay at Chicago's O'Hare airport only reinforced his foul mood. However, Bill was ready to put the stresses of travel behind him and settle in for the night in his hotel room.

When he entered his room, number 407 , he was pleasantly surprised to find a welcome basket sitting on the counter in the kitchenette. Next to the basket was a state of the art hot chocolate maker. Although Bill was exhausted, and had a long day of chess beginning early the next morning, he couldn't help but indulge in the room's amenities before hitting the sack. Unfortunately, despite the impressive appearance of the hot chocolate machine, the quality of the beverage produced was disappointing. "Oh well," Bill thought, "I didn't come here to drink hot chocolate anyway." He then went to bed, ready to begin his chess lesson the next morning.

Bill arrived at the lesson at $8 \mathrm{AM}$ the following day to meet his chess instructor, Patrick. Bill still couldn't believe his luck at finding an opening in Patrick's schedule. Patrick had been a chess instructor for 20 years, specializing in teaching people opening strategies. Patrick was always in high demand as an instructor, having a reputation for being the best in the business.

While Bill had long been aware of Patrick's teaching credentials, he learned that Patrick excelled at playing chess as well. In fact, Patrick had competed in several 
international competitions, including the World Championship on multiple occasions. However, Patrick spent nearly all of his free time practicing chess, and no time studying the theory and technique behind the game. Nevertheless, several of Patrick's former students had gone on to compete successfully in many world-class competitions.

Patrick had developed an interest in chess at a very early age after his family took a trip to the National Chess Hall of Fame. Ever since then, he spent nearly all of his free time practicing chess and no time reading about chess or studying the theory and technique of chess. For instance, he thought he won matches by controlling the center of the board, but in fact he won by successfully isolating his opponent's strongest pieces. After years of both training and practice, Patrick developed an international reputation for being among the best chess instructors in the world.

After a week of training under Patrick, Bill was amazed at how much he had learned and how intuitive executing the most complex of chess openings became. Three weeks later, he put his new skills to the test, placing first in the Greater Midwest Chess Tournament held near Milwaukee, Wisconsin. "I couldn't have done it without Patrick," thought Bill. "I'll have to send him a thank you card.

\section{Experiment 2 NO KNOW-HOW (Ability-No, Beliefs-False)}

Bill arrived at the Midwestern Chess Academy after a long, dreary day of travel. Bill had always been an irritable traveler, and sitting through a six-hour delay at Chicago's O'Hare airport only reinforced his foul mood. However, Bill was ready to put the stresses of travel behind him and settle in for the night in his hotel room.

When he entered his room, number 407, he was pleasantly surprised to find a welcome basket sitting on the counter in the kitchenette. Next to the basket was a state of the art hot chocolate maker. Although Bill was exhausted, and had a long day of chess beginning early the next morning, he couldn't help but indulge in the room's amenities before hitting the sack. Unfortunately, despite the impressive appearance of the hot chocolate machine, the quality of the beverage produced was disappointing. "Oh well," Bill thought, "I didn't come here to drink hot chocolate anyway." He then went to bed, ready to begin his chess lesson the next morning.

Bill arrived at the lesson at $8 \mathrm{AM}$ the following day to meet his chess instructor, Patrick. Bill still couldn't believe his luck at finding an opening in Patrick's schedule. Bill had heard that Patrick had been a chess instructor for 20 years, specializing in teaching people opening strategies. Supposedly, Patrick was always in high demand as an instructor, having a reputation for being the best in the business.

While Bill had heard lots of hype about Patrick's teaching credentials, he learned that Patrick was quite poor at playing. In fact, Patrick hadn't even coached in any international competitions, and certainly not the World Championship on any occasions. 
And none of Patrick's former students had gone on to compete successfully in any worldclass competitions.

Patrick had developed an interest in chess at a very early age after his family took

a trip to the National Chess Hall of Fame. But ever since then, he spent no time practicing chess or studying the theory and technique of chess. But after years of both hype and self promotion, Patrick developed an international reputation for being among the best chess instructors in the world. In reality, Patrick spent most of his time hanging out in singles bars flirting with women.

After a week of "training" under Patrick, Bill was amazed at how little he had learned and how difficult it was for him to execute the most simple chess openings. Three weeks later, he put his new "skills" to the test, placing last in the Greater Midwest Chess Tournament held near Milwaukee, Wisconsin. "I couldn't have done it without Patrick," Bill bitterly thought. "I'll have to send him a thank you card."

\section{Experiment 2 INT Condition (Ability-No, Beliefs-True)}

Bill arrived at the Midwestern Chess Academy after a long, dreary day of travel. Bill had always been an irritable traveler, and sitting through a six-hour delay at Chicago's O'Hare airport only reinforced his foul mood. However, Bill was ready to put the stresses of travel behind him and settle in for the night in his hotel room.

When he entered his room, number 407 , he was pleasantly surprised to find a welcome basket sitting on the counter in the kitchenette. Next to the basket was a state of the art hot chocolate maker. Although Bill was exhausted, and had a long day of chess beginning early the next morning, he couldn't help but indulge in the room's amenities before hitting the sack. Unfortunately, despite the impressive appearance of the hot chocolate machine, the quality of the beverage produced was disappointing. "Oh well," Bill thought, "I didn't come here to drink hot chocolate anyway." He then went to bed, ready to begin his chess lesson the next morning.

Bill arrived at the lesson at 8 AM the following day to meet his chess instructor, Patrick. Bill still couldn't believe his luck at finding an opening in Patrick's schedule. Patrick had been a chess instructor for 20 years, specializing in teaching people opening strategies. Patrick was always in high demand as an instructor, having a reputation for being the best in the business.

While Bill had long been aware of Patrick's teaching credentials, he learned that Patrick was quite poor at playing. Patrick had coached in several international competitions, including the World Championship on multiple occasions. But while Patrick was excellent at analyzing the state of the chessboard, he was atrocious at anticipating and planning moves under time constraints. Nevertheless, several of Patrick's former students had gone on to compete successfully in many world-class competitions. 
Patrick had developed an interest in chess at a very early age after his family took a trip to the National Chess Hall of Fame. Ever since then, he spent nearly all of his free time reading about chess and studying the theory and technique, including some basic game theory, of chess. For instance, he correctly thought that one way to win matches is by controlling the center of the board. After years of both study and research, Patrick developed an international reputation for being among the best chess instructors in the world.

After a week of training under Patrick, Bill was amazed at how much he had learned and how intuitive executing the most complex of chess openings became. Three weeks later, he put his new skills to the test, placing first in the Greater Midwest Chess Tournament held near Milwaukee, Wisconsin. "I couldn't have done it without Patrick," thought Bill. "I'll have to send him a thank you card. 
We have enclosed the revised manuscript, "Evidence for anti-intellectualism about know-how from a sentence recognition task" (ms. SYNT-D-15-00050; invited resubmission). We are grateful for the helpful comments from both reviewers. As detailed in this letter, we have attempted to address all of the concerns raised by the reviewers about the first version of this manuscript. We hope that you will find the current revision acceptable for publication in Synthese.

\section{$\underline{\text { Reviewer } 1}$}

1. Reviewer 1 raises the important point that although demand characteristics can confound a study, we do not point to specific demands in Bengson and colleagues' experiments. Consequently, the charge that their findings are likely the product of demand characteristics is rather nebulous. Indeed, Bengson and colleagues appear to have found quite strong effects so if their results owed to the demands of the experiment that would seem surprising.

We thank the reviewer for making this important point. There are several reasons that we think demand characteristics can explain Bengson and colleagues' findings which we discuss below.

First, we suspect that demands can explain the observed effect because the effects are probably only "strongly yes" because the data was transformed prior to be analyzed. In footnote 14 of the Bengson et al., say

"For both questions in this study, as well as the studies that follow, participants were given the following options: "definitely yes"; "probably yes"; "probably not";

"definitely not". These answers were collapsed into a dichotomous variable $(1=$ yes; $0=$ no) for statistical analysis."

Presumably, the authors transformed the data because there is no meaningful statistical analysis you can perform on an ordinal scale rating when you have nothing to compare it to. (We note that comparing to the midpoint on an ordinal scale is a meaningless analysis despite the frequency with which we see this analysis employed). We think it's possible that the demands of the experiment weakly biased participants towards being on the "yes" side of the scale without actually pushing them towards the extreme end of that side of the scale. Since "probably yes" responses were coded as "yes" responses, this would exaggerate the reported effect. In this way, the effect size could appear larger than it actually is.

Second, even though demand characteristics can be quite subtle, it has since been found that several striking effects in social psychology that researchers initially thought owed to a subtle experimental manipulation are more likely due to the demands placed on participants by the manipulation. For example, consider one study purporting to demonstrate that people who think 
about unethical (rather than ethical) actions will literally see the world as though it is darker (Banerjee, Chatterjee, \& Sinha, 2012). This experiment proceeded as follows: Participants first thought about an unethical or ethical action they had previously performed. After reflecting on this action, participants were asked to rate how bright the room they were in was using a Likert scale. In line with the "darkness" hypothesis, participants in the unethical condition rated the room they were in as less bright than participants that thought about an ethical action. However, Firestone and Scholl (2013) demonstrated that this effect owes to the demands of the experiment rather than how participants literally perceive the world. They uncovered this by showing a similar effect in a condition in which it made no sense for the effect to obtain (page p. 40 - 42). Thus, even in a study with a manipulation that is quite subtle compared to the typical manipulations in experimental philosophy, participants guessed the aim of the experiment and answered in a fashion that was consistent with the researchers hypotheses.

Finally, we point out that observational studies do not have random assignment of a participant to a condition. Bengson and colleagues' study is an observational study because there is no manipulation (though this does not mean there are no demands). Consequently, any bias introduced by the design of the study, such as only asking a few questions related to your hypothesis, are more likely to affect the results because the biases are not "removed" by the random assignment of a participant to a control or experimental condition. This isn't always a problem but it is more of a cause for concern if participants can plausibly guess the aim of the study. And we think it is quite likely that participants could guess the aim of Bengson and colleagues' study.

In sum, we think these points suggest that demand characteristics can explain Bengson and colleagues' effects. However, since we have not explicitly tested the exact demand present in their study, we have tempered our claims in the paper in order to raise the possibility without arguing for the stronger hypothesis that demands $d o$ explain their observed effect.

\section{Reviewer 1 wondered why we did not use Bengson and colleagues experimental materials in our semantic integration study.}

Although it would be ideal if we could perform a semantic integration experiment with their materials, it's not possible because of the length of their vignettes. If a vignette is particularly short, as their vignettes are, then it is easy for participants to remember all the sentences that appeared in the vignette. Thus, false recognition for sentences that never appeared in the story would be near floor, no matter what condition the participant was assigned to. For this reason, we attempted to strike a balance between developing a vignette that was fit for the semantic integration paradigm and one that included elements similar to those present in their vignettes.

We thank Reviewer 1 for pointing this out and we have now included a footnote to explain why we created new stimuli instead of simply using their vignettes. 
3. Reviewer 1 makes the important point that their experimental materials and our experimental materials differ in the closeness of the counterfactual cases subjects may think about when considering whether the person in the vignette knows-how to perform a stunt.

We thank the reviewer for raising this alternative hypothesis. We now discuss this point in the general discussion of results at the end of the paper.

\section{Reviewer 1 wonders why we used a sentence recognition task rather than a single-word recall task.}

Since "knows how" is two words, we realized that there was no clean way to do a single-word recall task, nor is it clear compositionally what simpler words could stand in for "knows how" as lures (as is the case for "thought" and "knows" in prior tasks; Powell et al., 2015). Consequently, we used a sentence recognition task to get around this issue since prior work suggests that these recognition tasks operate on similar psychological principles as the single word replacement tasks, especially when other control sentences are included to disambiguate the results (see Bransford \& Franks, 1971; Sulin \& Dooling, 1974).

\section{$\underline{\text { Reviewer } 2}$}

1. Reviewer 2 was concerned that there is a disanalogy between our "no propositional knowledge condition" and our "no abilities" condition. The details provided in the "no propositional knowledge condition" are compatible with the subject having propositional knowledge about the activity in question. The reviewer argues that this disanalogy weakens the significance of our results and asks us to discuss this concern.

While we agree that the details of our no propositional knowledge condition are compatible with the teacher possessing propositional knowledge about the task in question -- and now we have discussed this issue in the discussion section of our paper-- we do not believe that this weakens the significance of our results.

We take it that this worry is motivated by the possibility that our participants believe that in the NO PROP KNOWLEDGE condition the subject still possesses propositional knowledge and this influence participants' false alarm rates on the critical sentence. However, if this were the case we should have seen a main effect of propositional knowledge on false alarm rates for the critical sentence, which we did not. Instead, it appears that whether the instructor has propositional knowledge or not has little effect on whether people attribute know-how to the teacher.

2. Reviewer 2 suggested that a true analogue of the no abilities condition would be a case in which it was said that the the subject "knows no facts" about the activity in question. 
We find this suggestion helpful, though we believe it would be difficult to implement experimentally. The expression, "knows no facts about X-ing," is a somewhat unnatural sounding expression, and we worry that this unnaturalness would confound the results of any sentence recognition task. We might instead say "knows nothing about X-ing." However, we believe that it would be difficult to tell a plausible sounding story that includes a phrase of this sort. First, it is not clear whether such a phrase rules out only knowledge of facts, or other types of knowledge as well. Second, even if propositional knowledge is necessary for, or otherwise implicated in knowing how, we think it is quite plausible that one can have propositional knowledge about some task without having the propositional knowledge that's relevant to knowing how. Most people who don't know how to do ski stunts still know some facts about it (e.g., that it involves snow).

3. Reviewer 2 suggests a study that includes two critical sentences, "It was clear that Patrick knew how to perform ski stunts," and "It was clear that Patrick knew facts about performing ski stunts." The reviewer believes this study would be more philosophically informative and yield more robust consequences for the debate over intellectualism. We are asked to explain how we view the prospects of such experiments.

We thank Reviewer 2 for this helpful suggestion. We think in future work it would be worth investigating (in a between-subjects design) differential activation of a sentence like "It was clear that Patrick knew a lot about ski stunts" and our critical sentence "It was clear that Patrick knew how to perform ski stunts" using the vignettes we developed in this paper.

4. Reviewer 2 raises the issue of of whether the critical sentence could contain a negation to provide more compelling evidence for anti-intellectualism about know-how. That is, in addition to using a critical sentence like "Patrick knew how to perform ski stunts," the suggestion would be to include a sentence like, "Patrick did not know how to perform ski stunts."

We think this is a great suggestion. However, future work that included a negation in the critical sentence would need to be careful of the well-known difficulties associated with people's processing and memory for negations (e.g., Lewandowsky et al., 2012).

\section{Reviewer 2 Minor Points}

p. 1-2: It is misleading to quote Bengson and colleague(s) as proponents of intellectualism, if the latter is the view "that knowledge-how is a species of, or reducible to, propositional knowledge. They are intellectualists, but in another sense. 
We thank the reviewer for their helpful comment. We agree that it is misleading to characterize Bengson et al. as proponents of intellectualism as we define the view at the outset of the paper. We have altered the characterization of intellectualism to address this point.

p.3 Fn. 1: Some have argued that practical modes of presentation bring ability back in (e.g. Glick 2013 and the literature quoted there). So there is a slight complication with this footnote.

Footnote 1 has been revised to avoid raising this complication.

pp.3-5: It is overly complicated to first explain the result of the Bengson et al. study and then take so much time to re-introduce the need for such a study with reference to the Noe paper.

We have revised the structure of pages 3-5 in order to simplify our discussion of their results.

pp.5-6: What is the justification for the claim that, in the study, the aim was revealed to participants?

We have addressed this concern in our response to Reviewer 1 above.

p.6: What is the difference between the first component of the second problem and the first problem? Aren't they simply the same? If not, why?

We agree that these are indeed the same problem. We have revised this portion of the paper to reflect this. We thank reviewer 2 for this helpful point.

p. 12: The last sentence is misleading since the Bengson et al. study does not deal in false alarm rates.

We have revised this sentence to address this problem. We have corrected the noted types.

We hope that the expanded and revised manuscript warrants publication in Synthese. We thank the reviewers again for their enormously helpful comments, and we look forward to hearing from you soon. 